\title{
Effects of recombinant human growth hormone on protein malnutrition and $I G F-1$ and $I L-2$ gene expression levels in chronic nephrotic syndrome
}

\author{
GUANG DAI $^{1 *}$, DONGHAI WANG ${ }^{1 *}$ and HUA DONG ${ }^{2}$ \\ ${ }^{1}$ Department of Nephrology, Zhumadian Central Hospital, Zhumadian, Henan 463000; ${ }^{2}$ Department of Nephrology, \\ The Affiliated Hospital of Binzhou Medical College, Binzhou, Shandong 256603, P.R. China
}

Received July 28, 2017; Accepted December 11, 2017

DOI: $10.3892 /$ etm.2018.5953

\begin{abstract}
The aim of the study was to investigate the effects of recombinant human growth hormone on protein malnutrition and insulin-like growth factor-1 $(I G F-1)$ and interleukin-2 (IL-2) gene expressions in chronic nephrotic syndrome. Eighty patients with chronic nephrotic syndrome were admitted to our hospital. The patients were included in the study period from January 2015 to December 2016 and were divided into two groups (40 cases in each group) according to the random number method. All the patients enrolled received symptomatic and supportive treatment. The observation group was injected subcutaneously with recombinant human growth hormone, while the control group was treated with Shenyankangfu tablets. The recovery time of the clinical symptoms, change in serum protein, caloric intake and protein metabolism after intervention were compared between the two groups. Changes in serum cystatin $C, I G F-I$ and $I L-2$ before intervention, and at 1 week, 1 month and 3 months after intervention were detected, and the adverse reactions in the two groups were observed during the treatment. After intervention, the improvement time of proteinuria, hypoproteinemia, edema and hyperlipidemia in the observation group was significantly shorter than that in the control group $(\mathrm{P}<0.05)$. The expression of transferrin, pre-albumin, albumin and total protein in the observation group was significantly superior increased compared to those in the observation group prior to intervention and the control group after intervention $(\mathrm{P}<0.05)$. In addition the caloric intake, protein intake and urea nitrogen survival
\end{abstract}

Correspondence to: Dr Hua Dong, Department of Nephrology, The Affiliated Hospital of Binzhou Medical College, 661 Huanghe Second Road, Binhai, Binzhou, Shandong 256603, P.R. China E-mail: zhong56397509@163.com

*Contributed equally

Key words: recombinant human growth hormone, nephrotic syndrome, protein malnutrition, insulin-like growth factor-1, interleukin-2 rate in the observation group were significantly superior to those in the observation group prior to intervention and the control group after intervention $(\mathrm{P}<0.05)$. At 1 week, 1 month and 3 months after intervention, the levels of serum cystatin $\mathrm{C}, I G F-1$ and $I L-2$ in the observation group were markedly obviously lower than those in the control group during the same period $(\mathrm{P}<0.05)$. The total proportion of allergy, systemic pruritus, nausea and vomiting, abdominal distension and abdominal pain in the observation group was obviously lower than that in the control group $(\mathrm{P}<0.05)$. Compared with the traditional Chinese medicine Shenyankangfu tablets applied in the control group, the recombinant human growth hormone used for patients with chronic nephrotic syndrome can improve the clinical symptoms more quickly, regulate the protein metabolism and reduce the inflammatory response in the body, which also has fewer adverse reactions and higher safety.

\section{Introduction}

Nephrotic syndrome is the most clinically common kidneyrelated disease at present, posing a serious threat to physical health (1). In its pathogenesis, immune dysfunction is the main pathogenic and initiative factors (2). At the same time, patients are often accompanied with malnutrition due to the loss of a large number of plasma proteins (3).

In the treatment of this disease, symptomatic and supportive treatment is dominant and nutritional support is strengthened for patients, as well as infection prevention, reduction of body aseptic inflammation and anti-immunosuppression (4). Recombinant human growth hormone is mainly secreted by the pituitary gland, which belongs to the common water-soluble protein in the body with the effects of promoting growth, development and metabolism of the body (5). In addition, it can strengthen the body's immune regulation function, and its therapeutic value in chronic nephrotic syndrome has been confirmed by the basic research (6).

In this study, the effects of recombinant human growth hormone on nutritional status and inflammatory factors, in patients with chronic nephrotic syndrome were investigated. The results showed that, chronic nephrotic syndrome can improve the clinical symptoms more rapidly, regulate the protein 
metabolism and reduce the inflammatory response in the body, which also has fewer adverse reactions and higher safety.

\section{Materials and methods}

General materials. Eighty patients with chronic nephrotic syndrome were admitted to our hospital, and were included in the study, from January 2015 to December 2016. All the patients were informed before enrollment and signed the informed consent. The study was approved by the Ethics Committee of the Zhumadian Central Hospital (Henan, China). Patients were aged 18-60 years and received education in junior high school and above. Those who were treated with glucocorticoid and/or immunosuppressor within 30 days before enrollment, complicated with mental illness, inflammation or cardiopulmonary insufficiency, hepatic dysfunction, systemic infection, immune system diseases due to other causes, malignant tumors, unclear pathogenesis or drug allergy or who refused to be enrolled were excluded. According to the random number method, the patients were divided into two groups (40 cases in each group). The observation group comprised 21 males and 19 females, aged 18-60 years, with an average of $35.3 \pm 2.1$ years, and onset time of nephrotic syndrome was 1 week to 5 months with an average of $1.5 \pm 0.2$ months. The control group comprised 23 males and 17 females, aged 18-60 years, with an average of $35.4 \pm 2.1$ years, and the onset time of nephrotic syndrome was 1 week to 5 months with an average of $1.5 \pm 0.3$ months. There were no statistically significant differences in the sex, age and onset time of nephrotic syndrome between the two groups $(\mathrm{P}>0.05)$.

Methods. The patients enrolled received symptomatic and supportive treatment, such as the application of diuretics, immunosuppressor, anti-inflammatory drugs and cytotoxic drugs. At the same time, patients complicated with infection were treated with antibacterial drugs for the prevention and treatment of infection, and anti-coagulation, regulation of plasma proteins, prevention and delay of renal failure and other treatments were also provided. On this basis, the observation group was injected subcutaneously with recombinant human growth hormone (Swiss Selangor Pharmaceutical Co., batch no. S2015010015) 3 times a week (4 units each time). Continuous treatment for 4 weeks was 1 course of treatment and the 3 courses of treatment constituted 1 treatment cycle. The control group was treated with Shenyankangfu tablets (Tianjin Tongrentang Group Co., Ltd., Tianjin, China; batch no. 201501132) at a dose of 5 tablets ( $0.48 \mathrm{~g} /$ tablets) each time, once in the morning, afternoon and evening. Continuous treatment for 1 month was 1 course of treatment and, the 3 courses of treatment constituted 1 treatment cycle.

Observational indexes. The recovery time of clinical symptoms, change in serum protein, the body's caloric intake and protein metabolism after intervention were compared between the two groups. The changes in serum cystatin $\mathrm{C}$, insulin-like growth factor-1 (IGF-1) and interleukin-2 (IL-2) before intervention, and at 1 week, 1 month and 3 months after intervention were detected. Adverse reactions in the two groups were observed during the treatment.

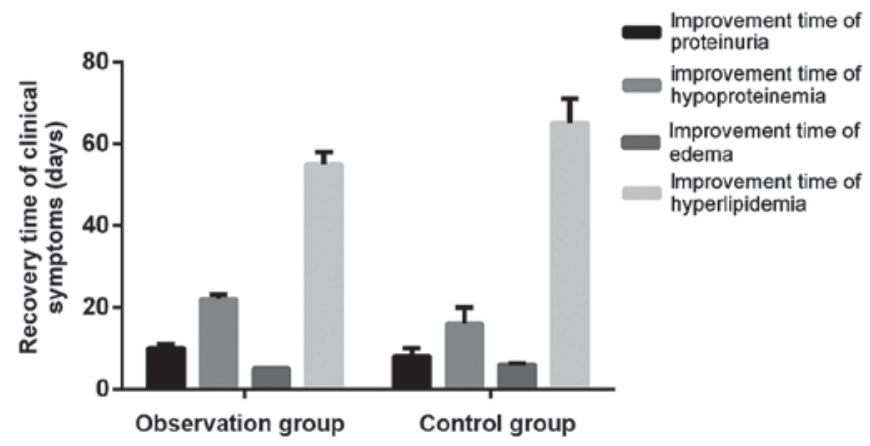

Figure 1. Comparison of recovery time of clinical symptoms after intervention between the two groups.

Evaluation methods. In clinical symptoms, the improvement of proteinuria, hypoproteinemia, edema and hyperlipidemia in nephrotic syndrome was observed. The normal level of proteinuria was $<3.5 \mathrm{~g} /$ day and that of plasma albumin was $>30 \mathrm{~g} / \mathrm{l}$. In serum lipid parameters, the level of total cholesterol, triglyceride and low-density lipoprotein was 2.8-5.17, 0.56-1.7 and 0-3.1 mmol/1, respectively, which was normal. Transferrin, prealbumin and albumin were detected using the enzyme-linked immunosorbent assay (ELISA), and the normal reference values were $2.20-4.0 \mathrm{~g} / \mathrm{l}(220-400 \mathrm{mg} / \mathrm{dl}), 280-360 \mathrm{mg} / \mathrm{l}$ and $35-50 \mathrm{~g} / \mathrm{l}$, respectively. The caloric intake was calculated according to the daily diet, combined with Calorie Counter; and the normal concentration of serum cystatin $\mathrm{C}$ in serum and plasma was 0.51-1.09 mg/l. IGF- 1 was detected using a spectrophotometer spectrophotometer (Hitachi, Tokyo, Japan) and its normal reference value was $80-485 \mu \mathrm{g} / 1 . I L-2$ was detected via ELISA and its normal reference value was $0.5-1.5 \mu \mathrm{g} / \mathrm{l}$.

Statistical analysis. Statistical Product and Service Solutions (SPSS) 21.0 (IBM, Armonk, NY, USA) software was used for statistical analysis. Measurement data were presented as mean \pm standard deviation. A t-test was used for the comparison of means between the two groups, while the Chi-square test was used for comparison of the ratio between the two groups. $\mathrm{P}<0.05$ was considered to indicate a statistically significant difference.

\section{Results}

Comparison of recovery time of clinical symptoms after intervention between the two groups. After intervention, the improvement time of proteinuria, hypoproteinemia, edema and hyperlipidemia in the observation group was significantly shorter than that in the control group $(\mathrm{t}=9.803,5.979,21.503$ and 17.481, P<0.05) (Fig. 1).

Comparison of serum protein changes between the two groups before and after intervention. There were no statistically significant differences in transferrin, pre-albumin, albumin and total protein between the two groups before intervention $(\mathrm{P}>0.05)$. After intervention, the expression of transferrin, pre-albumin, albumin and total protein in the observation group was significantly increased compared to that in the observation group before intervention and, the control group after intervention $(\mathrm{P}<0.05)$ (Table I). 
Table I. Comparison of serum protein changes between the two groups before and after intervention (g/l, mean $\pm \mathrm{SD})$.

\begin{tabular}{|c|c|c|c|c|}
\hline Groups & Transferrin & Pre-albumin & Albumin & Total protein \\
\hline \multicolumn{5}{|l|}{ Observation group } \\
\hline Before intervention & $1.52 \pm 0.03$ & $0.20 \pm 0.01$ & $32.15 \pm 0.09$ & $56.89 \pm 0.15$ \\
\hline After intervention & $1.98 \pm 0.06^{\mathrm{a}, \mathrm{b}}$ & $0.26 \pm 0.01^{\mathrm{a}, \mathrm{b}}$ & $38.98 \pm 0.12^{\mathrm{a}, \mathrm{b}}$ & $69.53 \pm 0.09^{a, b}$ \\
\hline \multicolumn{5}{|l|}{ Control group } \\
\hline Before intervention & $1.53 \pm 0.03$ & $0.21 \pm 0.01$ & $32.16 \pm 0.09$ & $56.90 \pm 0.15$ \\
\hline After intervention & $1.73 \pm 0.04^{\mathrm{a}}$ & $0.03 \pm 0.01^{\mathrm{a}}$ & $34.56 \pm 0.07^{\mathrm{a}}$ & $66.33 \pm 0.07^{\mathrm{a}}$ \\
\hline
\end{tabular}

${ }^{\mathrm{a}} \mathrm{P}<0.05$, compared with that before intervention; ${ }^{\mathrm{P}}<0.05$, compared with the control group.

Table II. Comparisons of caloric intake and protein metabolism in the body before and after intervention (mean \pm SD).

\begin{tabular}{|c|c|c|c|}
\hline Groups & $\begin{array}{l}\text { Caloric intake } \\
{[\mathrm{kJ} /(\mathrm{kg} \cdot \text { day })]}\end{array}$ & $\begin{array}{c}\text { Protein intake } \\
{[\mathrm{g} /(\mathrm{kg} \cdot \mathrm{day})]}\end{array}$ & $\begin{array}{c}\text { Urea nitrogen } \\
\text { survival rate }(\mathrm{g} / \text { day })\end{array}$ \\
\hline \multicolumn{4}{|l|}{ Observation group } \\
\hline Before intervention & $123.5 \pm 2.5$ & $0.78 \pm 0.11$ & $12.3 \pm 0.05$ \\
\hline After intervention & $149.6 \pm 3.3^{\mathrm{a}, \mathrm{b}}$ & $0.96 \pm 0.12^{\mathrm{a}, \mathrm{b}}$ & $15.1 \pm 0.12^{\mathrm{a}, \mathrm{b}}$ \\
\hline \multicolumn{4}{|l|}{ Control group } \\
\hline Before intervention & $124.0 \pm 2.5$ & $0.79 \pm 0.11$ & $12.6 \pm 0.05$ \\
\hline After intervention & $133.5 \pm 2.6^{\mathrm{a}}$ & $0.86 \pm 0.13^{\mathrm{a}}$ & $13.3 .35 \pm 0.08^{\mathrm{a}}$ \\
\hline
\end{tabular}

${ }^{\mathrm{a}} \mathrm{P}<0.05$, compared with that before intervention; ${ }^{\mathrm{b}} \mathrm{P}<0.05$ compared with the control group.

Comparisons of caloric intake and protein metabolism in the body before and after intervention. There were no statistically significant differences in the caloric intake, protein intake and urea nitrogen survival rate between the two groups before intervention $(\mathrm{P}>0.05)$. After intervention, the caloric intake, protein intake and urea nitrogen survival rate in the observation group were significantly superior to those in the observation group before intervention and the control group after intervention $(\mathrm{P}<0.05)$ (Table II).

Changes in serum cystatin C levels in the two groups during the intervention. There was no statistically significant difference in the serum cystatin $\mathrm{C}$ level between the two groups before intervention $(\mathrm{P}>0.05)$. At 1 week, 1 month and 3 months after intervention, the levels of serum cystatin $\mathrm{C}$ in the observation group were $1.15 \pm 0.02,1.02 \pm 0.01$ and $0.69 \pm 0.01 \mathrm{mg} / 1$, which were significantly lower than those in the control group $(1.26 \pm 0.03,1.21 \pm 0.02$ and $1.10 \pm 0.02 \mathrm{mg} / \mathrm{l})$ during the same period $(\mathrm{t}=19.295,53.740$ and 166.877 , $\mathrm{P}<0.05$ ) (Fig. 2).

Changes in the IGF-1 level in the two groups during intervention. There was no statistically significant difference in the IGF- 1 level between the two groups before intervention $(\mathrm{P}>0.05)$. At 1 week, 1 month and 3 months after intervention, the levels of $I G F-1$ in the observation group were 154.2 \pm 3.3 , $169.6 \pm 3.6$ and $183.6 \pm 4.3 \mu \mathrm{g} / 1$, which were significantly lower than those in the control group $(146.3 \pm 3.0,156.5 \pm 3.2$ and

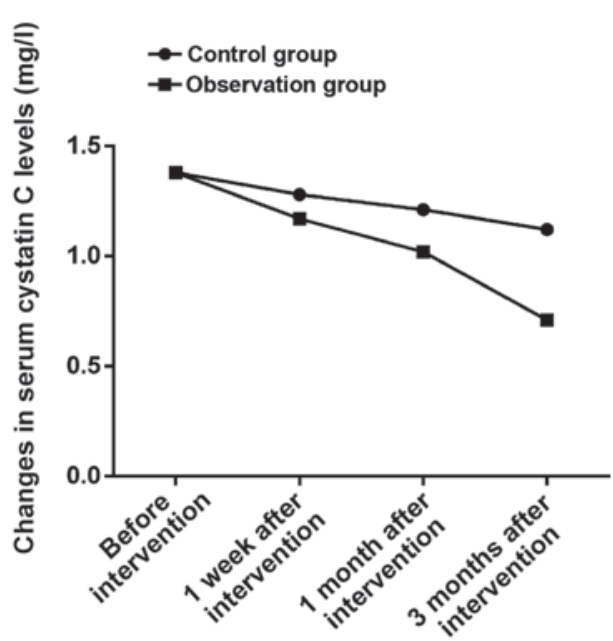

Figure 2. Changes in serum cystatin $\mathrm{C}$ levels in the two groups during the intervention. There is no statistically significant difference in the serum cystatin $\mathrm{C}$ level between the two groups before intervention $(\mathrm{P}>0.05)$. At 1 week, 1 month and 3 months after intervention, the levels of serum cystatin $\mathrm{C}$ in the observation group are obviously lower than those in the control group during the same period $(\mathrm{P}<0.05)$.

169.4 $\pm 3.4 \mu \mathrm{g} / \mathrm{l})$ during the same period $(\mathrm{t}=11.162,16.856$ and 16.254, $\mathrm{P}<0.05$ ) (Fig. 3).

Changes in the IL-2 level in the two groups during the intervention. There was no statistically significant differences in 
Table III. Comparison of adverse reactions between the two groups during treatment [n (\%)].

\begin{tabular}{|c|c|c|c|c|c|}
\hline Variable & Allergy & $\begin{array}{l}\text { Systemic } \\
\text { pruritus }\end{array}$ & $\begin{array}{l}\text { Nausea and } \\
\text { vomiting }\end{array}$ & $\begin{array}{l}\text { Abdominal distension } \\
\text { and abdominal pain }\end{array}$ & $\begin{array}{c}\text { Total incidence } \\
\text { rate }\end{array}$ \\
\hline Observation group & 1 & 1 & 1 & 1 & $4(10.0 \%)$ \\
\hline Control group & 3 & 4 & 3 & 3 & $13(32.5 \%)$ \\
\hline$\chi^{2}$ test & & & & & 4.781 \\
\hline P-value & & & & & 0.029 \\
\hline
\end{tabular}

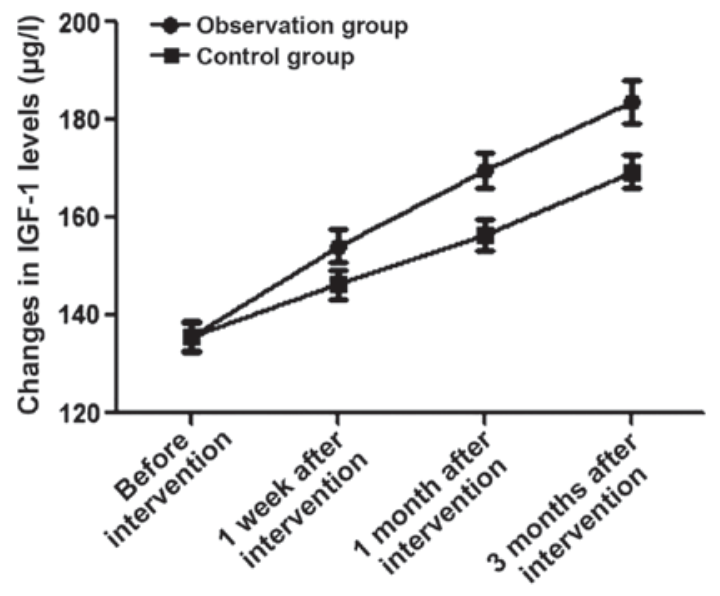

Figure 3. Changes in the IGF-1 levels in the two groups during the intervention. There is no statistically significant difference in the IGF-1 level between the two groups before intervention $(\mathrm{P}>0.05)$. At 1 week, 1 month and 3 months after intervention, the levels of $I G F-1$ in the observation group are obviously lower than those in the control group during the same period $(\mathrm{P}<0.05)$.

the $I L-2$ level between the two groups before intervention $(\mathrm{P}>0.05)$. At 1 week, 1 month and 3 months after intervention, the levels of $I L-2$ in the observation group were $0.68 \pm 0.04$, $0.75 \pm 0.05$ and $0.86 \pm 0.06 \mu \mathrm{g} / 1$, which were significantly lower than those in the control group $(0.63 \pm 0.03,0.68 \pm 0.06$ and $0.73 \pm 0.07 \mu \mathrm{g} / \mathrm{l})$ during the same period $(\mathrm{t}=6.325,5.668$ and 8.918, $\mathrm{P}<0.05$ ) (Fig. 4).

Comparison of adverse reactions between the two groups during treatment. The total proportion of allergy, systemic pruritus, nausea and vomiting, abdominal distension and abdominal pain in the observation group was obviously lower than that in the control group $(\mathrm{P}<0.05)$ (Table III).

\section{Discussion}

The body of patients with nephrotic syndrome occurs mostly at an accelerated catabolism status, combined with increased protein consumption and loss and malnutrition (7). With the progression of disease, they are accompanied with inflammatory hypoproteinemia and hyperlipidemia (8). Additionally, the body's nutritional metabolism is in a state of disorder, and long-term malnutrition seriously affects the prognosis of patients (9). Previous findings have shown that hypoproteinemia is treated by the infusion of exogenous human albumin for symptomatic support treatment; however, albumin is expensive (10). Additionally, there are certain

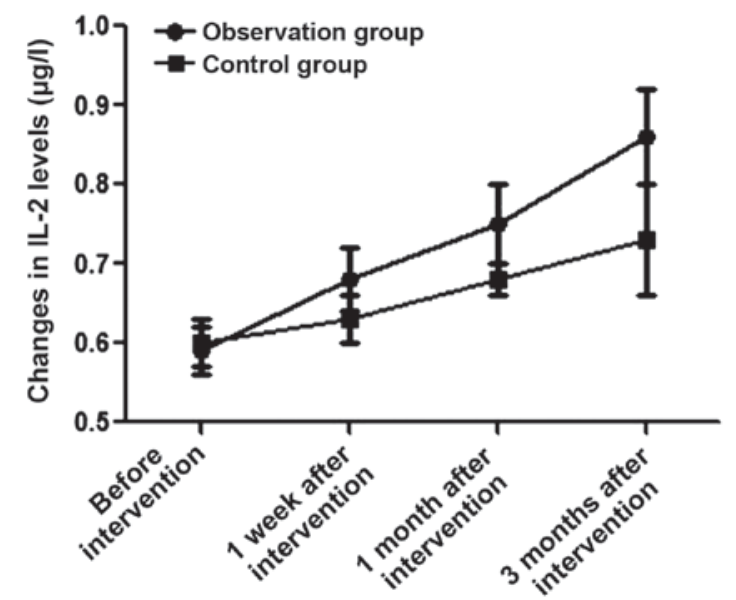

Figure 4. Changes in $I L-2$ levels in the two groups during the intervention. There is no statistically significant difference in the $I L-2$ level between the two groups before intervention $(\mathrm{P}>0.05)$. At 1 week, 1 month and 3 months after intervention, the levels of $I L-2$ in the observation group are obviously lower than those in the control group during the same period $(\mathrm{P}<0.05)$.

infusion complications, leading to loss of albumin while the total time of maintaining plasma protein after infusion is short (11). Therefore, it cannot fundamentally correct the hypoproteinemia and malnutrition of the body. Traditional Chinese medicine has also been applied in recent studies (12). However its treatment period was long, taking effect slowly over a short-term period and patient treatment compliance was poor (13). Long-term medication has a negative impact on renal function (14). Therefore, a clinically effective method with rapid effect is needed for nephrotic syndrome at present (15), especially for hypoproteinemia and increased inflammation in the body (16).

In this study, based on conventional treatment, patients with nephrotic syndrome in the observation group were treated with recombinant human growth hormone, while those in the control group were treated with traditional Chinese medicine Shenyankangfu tablets. The comparison of recovery time of clinical symptoms between the two groups after intervention showed that the improvement time of proteinuria, hypoproteinemia, edema and hyperlipidemia in the observation group after intervention was significantly shorter than that in the control group, indicating that the application of recombinant human growth hormone can improve the clinical symptoms of patients more quickly. In addition, the study on protein metabolism and caloric intake in the body before and after intervention revealed that the transferrin, pre-albumin, albumin and total protein, and caloric intake, protein intake 
and urea nitrogen survival rate in the observation group after intervention were significantly superior to those in the observation group before intervention and the control group after intervention, suggesting that the application of recombinant human growth hormone in patients with chronic nephrotic syndrome can effectively improve the patient's protein metabolism and maintain the positive nitrogen balance compared with the traditional Chinese medicine Shenyankangfu tablets in the control group. At the same time, the study on changes in serum cystatin $\mathrm{C}, I G F-1$ and $I L-2$ levels in the two groups during intervention showed that at 1 week, 1 month and 3 months after intervention, the levels of serum cystatin $\mathrm{C}$, $I G F-1$ and $I L-2$ in the observation group were obviously lower than those in the control group during the same period, indicating that application of the recombinant human growth hormone in patients with chronic nephrotic syndrome has a positive significance effect in improving glomerular filtration and reabsorption and reducing the body's inflammatory response. Finally, it was found in the comparisons of adverse reactions in the two groups during the treatment that the total proportion of allergy, systemic pruritus, nausea and vomiting, abdominal distension and abdominal pain in the observation group was obviously lower than that in the control group, suggesting that the intramuscular injection of recombinant human growth hormone has fewer adverse reactions and higher safety.

Recombinant human growth hormone is a kind of protein synthesis-promoting hormone in the body, which can reduce protein catabolism, reduce urea nitrogen excretion and promote the fat metabolism in the body (17), thereby improving the efficiency of protein synthesis. In addition, the recombinant human growth hormone has a certain effect of improving the immune function and reducing the incidence of infection (18). Through the indirect growth-promoting effect and direct anti-insulin function, it is used to improve the body's growth and development, increase the protein synthesis rate, enhance the albumin messenger RNA synthesis in liver (19), improve the amino acid utilization of muscle tissues, and promote the body's anabolism (20).

In conclusion, compared with the traditional Chinese medicine Shenyankangfu tablets applied in the control group, the recombinant human growth hormone used for patients with chronic nephrotic syndrome can improve the clinical symptoms more quickly, regulate the protein metabolism and reduce the inflammatory response in the body, which also has less adverse reactions and higher safety.

\section{Acknowledgements}

Not applicable.

\section{Funding}

No funding was received.

\section{Availability of data and materials}

The datasets used and/or analyzed during the present study are available from the corresponding author on reasonable request.

\section{Authors' contributions}

GD was involved in drafting the manuscript and data analysis. DW helped with acquisition of data. HD performed and analyzed ELISA. All authors read and approved the final manuscript.

\section{Ethics approval and consent to participate}

The study was approved by the Ethics Committee of Zhumadian Central Hospital (Zhumadian, China). Written informed consents were signed by the patients and/or guardians.

\section{Consent for publication}

Not applicable.

\section{Competing interests}

The authors declare that they have no competing interests.

\section{References}

1. Akchurin OM, Kogon AJ, Kumar J, Sethna CB, Hammad HT, Christos PJ, Mahan JD, Greenbaum LA and Woroniecki R: Approach to growth hormone therapy in children with chronic kidney disease varies across North America: The Midwest Pediatric Nephrology Consortium report. BMC Nephrol 18: 181, 2017.

2. Cho SM, Lee SH, Lee D, Lee JH, Chang GT, Kim H and Lee JY: The Korean herbal formulation Yukmijihwangtang stimulates longitudinal bone growth in animal models. BMC Complement Altern Med 17: 239, 2017

3. Cernaro V, Lucisano S, Canale V, Bruzzese A, Caccamo D, Costantino G, Buemi M and Santoro D: Acetate-free biofiltration to remove fibroblast growth factor 23 in hemodialysis patients: A pilot study. J Nephrol 11: 1007-1010, 2017.

4. Johar DR and Bernstein LH: Biomarkers of stress-mediated metabolic deregulation in diabetes mellitus. Diabetes Res Clin Pract 126: 222-229, 2017.

5. Hong JT, Son DJ, Lee CK, Yoon DY, Lee DH and Park MH: Interleukin 32, inflammation and cancer. Pharmacol Ther 174: 127-137, 2017.

6. Stephen J, Vilboux T, Mian L, Kuptanon C, Sinclair CM, Yildirimli D, Maynard DM, Bryant J, Fischer R, Vemulapalli M, et al; NISC Comparative Sequencing Program: Mutations in KIAA0753 cause Joubert syndrome associated with growth hormone deficiency. Hum Genet 136: 399-408, 2017.

7. Fragiadaki M,Lannoy M, Themanns M, Maurer B, Leonhard WN, Peters DJ, Moriggl R and Ong AC: STAT5 drives abnormal proliferation in autosomal dominant polycystic kidney disease. Kidney Int 91: 575-586, 2017.

8. Othman EM, Naseem M, Awad E, Dandekar T and Stopper H: The plant hormone cytokinin confers protection against oxidative stress in mammalian cells. PLoS One 11: e0168386, 2016.

9. Curran IH, Liston V, Nunnikhoven A, Caldwell D, Scuby MJ, Pantazopoulos P, Rawn DF, Coady L, Armstrong C, Lefebvre DE, et al: Toxicologic effects of 28-day dietary exposure to the flame retardant 1,2-dibromo-4-(1,2-dibromoethyl)-cyclohexane (TBECH) in F344 rats. Toxicology 377: 1-13, 2017.

10. Bu P, Le Y, Zhang Y and Cheng X: Hormonal and chemical regulation of the Glut9 transporter in mice. J Pharmacol Exp Ther 360: 206-214, 2017.

11. Liu Y, Dutra EH, Reichenberger EJ and Chen IP: Dietary phosphate supplement does not rescue skeletal phenotype in a mouse model for craniometaphyseal dysplasia. J Negat Results Biomed 15: 18, 2016.

12. Batra J, Buttar RS, Kaur P, Kreimerman J and Melamed ML: FGF-23 and cardiovascular disease: Review of literature. Curr Opin Endocrinol Diabetes Obes 23: 423-429, 2016. 
13. Zvereva I, Semenistaya E, Krotov G and Rodchenkov G: Comparison of various in vitro model systems of the metabolism of synthetic doping peptides: Proteolytic enzymes, human blood serum, liver and kidney microsomes and liver S9 fraction. J Proteomics 149: 85-97, 2016.

14. Liao S, Vickers MH, Evans A, Stanley JL, Baker PN and Perry JK: Comparison of pulsatile vs. continuous administration of human placental growth hormone in female C57BL/6J mice. Endocrine 54: 169-181, 2016.

15. Kobalava Z: SP 04-1 The role of natriuretic peptides in the pathogenesis of cardiovascular diseases. J Hypertens 3 (Suppl 1): e377, 2016.

16. Morgan SJ,Neumann S, Marcus-Samuels B and Gershengorn MC: Thyrotropin and insulin-like growth factor 1 receptor crosstalk upregulates sodium-iodide symporter expression in primary cultures of human thyrocytes. Thyroid 26: 1794-1803, 2016.

17. De Angelis M, GiesertF, Finan B, Clemmensen C, MüllerTD, VogtWeisenhorn D, Tschöp MH and Schramm KW: Determination of thyroid hormones in mouse tissues by isotope-dilution microflow liquid chromatography-mass spectrometry method. J Chromatogr B Analyt Technol Biomed Life Sci 1033-1034: 413-420, 2016.
18. Czarnecka AM, Matak D, Szymanski L, Czarnecka KH, Lewicki S, Zdanowski R, Brzezianska-Lasota E and Szczylik C: Triiodothyronine regulates cell growth and survival in renal cell cancer. Int J Oncol 49: 1666-1678, 2016.

19. Sexton DJ, O'Reilly MW, Geoghegan P, Kinsella SM, Moran PJ and O'Regan AW: Serum fibroblastic growth factor 23 in acute Sarcoidosis and normal kidney function. Sarcoidosis Vasc Diffuse Lung Dis 33: 139-142, 2016.

20. Nguyen-Yamamoto L, Karaplis AC, St-Arnaud R and Goltzman D: Fibroblast growth factor 23 regulation by systemic and local osteoblast-synthesized 1,25-dihydroxyvitamin D. J Am Soc Nephrol 28: 586-597, 2017.

This work is licensed under a Creative Commons Attribution-NonCommercial-NoDerivatives 4.0 International (CC BY-NC-ND 4.0) License. 